\title{
The role of information systems usage in enhancing port logistics performance: evidence from the Dar Es Salaam port, Tanzania
}

\author{
James Mlimbila and Ulingeta O. L. Mbamba* (D)
}

\author{
* Correspondence: ulingeta. \\ mbamba@gmail.com \\ University of Dar es Salaam, Dar es \\ Salaam, Tanzania
}

\begin{abstract}
This study investigated the role of information systems usage in enhancing port logistics performance using the port of Dar es Salaam, Tanzania, as an example. Specifically, the study examined the role of information systems usage in contributing to reducing shipping and trucking costs, improving on-time delivery of goods and services, increasing trade volume, and enhancing organisational logistics capability. The study employed a quantitative approach, with questionnaires deployed to gather data about information systems usage and the attendant effects. The reliability was measured using Cronbach's alpha. A canonical correlation analysis was performed to estimate the relationship of information systems usage to the port logistics performance. The study established that relationships exist between information systems usage and the perceived decrease in shipping and trucking costs, timely delivery of goods and services, perceived increase in trade volume, and enhanced organisational logistics capability. Based on these findings, the study recommends that ports consider building the capacity of their employees to utilise and manage information systems much more effectively and efficiently to increase the port's performance.
\end{abstract}

Keywords: Port logistics performance, Information systems usage, Organisational capability

\section{Introduction}

\section{Background of the research problem}

World trade, in our increasingly globalised and networked economy, depends on the rapid and timely transportation of goods from manufacturing places to market areas (Gidado 2015). In this regard, port activities and transportation network operations are inseparable, as good performance of the port is linked to its information systems usage (Wilson et al. 2015). Port congestion in Africa is an inevitable seasonal occurrence that is largely associated with improper planning and inadequate equipment or infrastructure that could otherwise support the transport and logistics network African ports need. Information systems constitute one of the solutions for addressing the challenges that occur in many processes that are important for the economic development of a nation (Pierson and Harner 2006). Information systems collect, supply, arrange, and

(c) The Author(s). 2018 Open Access This article is distributed under the terms of the Creative Commons Attribution 4.0 International License (http://creativecommons.org/licenses/by/4.0/), which permits unrestricted use, distribution, and reproduction in any medium, provided you give appropriate credit to the original author(s) and the source, provide a link to the Creative Commons license, and indicate if changes were made. 
use information to ensure the efficiency and effectiveness of an organisation's operations (Pierson and Harner 2006). According to Nowduri (2011), information systems enable management to quickly make decisions about different issues in the organisation. These information systems have become important in logistics service (Salin 2000) and entail a significant tool to reduce costs and effectively serve clients through better customisation of the service provided (Salin 2000). The basic purpose of any information system is to help its users obtain a certain type of value from the information in the systems, regardless of the types of information stored or desired value type. The integration of information systems in logistics has contributed to competitive supply chains that accord certain companies competitive edges in the market, with new methods implemented to prevent any inherent danger and loss of life (Weiss 2011).

Dar es Salaam port, owned by the Tanzania Ports Authority, is Tanzania's principal port, with a rated capacity of 4.1 million tonnes dry cargo and 6.0 million tonnes bulk liquid cargo (Tanzania Ports Authority 2017). Improved efficiency at the port can translate into additional tonnage of imports and exports. In fact, the volume of cargo has continued to record an upward trend, partly due to an increase in the use of information systems. The port handles almost all of Tanzania's international trade cargo and serves its landlocked neighbouring countries of Malawi, Zambia, the Democratic Republic of the Congo, Burundi, Rwanda and Uganda. These countries are connected to the port through two railway systems and road networks, in addition to a pipeline in the case of Zambia.

However, the delay in cargo clearance and the resultant congestion at the port of Dar es Salaam has become a matter of serious concern to all users of the port (Raballand et al. 2012, Daudi 2010, Kunaka et al. 2016). As Dar es Salaam is a major port that serves neighbouring land-locked countries, the Tanzania Ports Authority management should ensure that port services satisfy regional customer needs, as congestion at the port results in the port losing a high percentage of its potential income. Potential income could come from Kenya, Uganda, South Sudan, the Democratic Republic of Congo, Zambia, Malawi, Mozambique, and even Zimbabwe. The changing business environment and globalisation continued to expose the port of Dar es Salaam to stiff competition, especially with the port of Mombasa in the north for cargo originating from and destined to Uganda, Rwanda, the Democratic Republic of Congo (Kivu Province), the northern part of Tanzania and South Sudan. To its south, Dar es Salaam port competes with the Mozambican ports of Nacala, Beira and Maputo and the South African port of Durban for Zambia, Malawi and the Democratic Republic of Congo (Katanga Province) cargo. In the west, it competes with the Namibian port of Walvis Bay and the Angolan port of Lobito for traffic with Zambia and the Democratic Republic of Congo (Katanga Province).

Overall, the application of information systems at a given port should facilitate process management and control of the flow of work, data interface to minimise the recapture of data (both within the organisation and with third parties), data validation to prevent the costs of rework, performance measurement to manage the activities undertaken and compliance with local regulatory requirements (Weiss 2011). Therefore, information systems in ports hold the potential for significant progress, particularly in business management and public administration, by harmonising the manner of doing business for both customs administrations and traders, hence greatly reducing the delivery times and allowing rapid access to information (Arnold et al. 2011). 
In fact, the advancement of information systems enables containers' operators to reduce the manual effort in providing services and facilitating the timely information flow and enhanced quality control in service and decision making (Kia et al. 2000, Ally and Mbamba 2009). Moreover, the use of computer simulations has simplified handling complex cargo facilities, leading to significant savings derived from the implementation of electronic devices in port terminals operation (Kia et al. 2000). Against this backdrop, this study investigated the role of information systems usage in port logistics performance using the Dar es Salaam port as a case study.

Of the several schools of thought regarding the influence of information systems usage on performance, a notable one is the productivity paradox, which claims that despite investments in information technology, there may be no corresponding productivity gains. The paradox has been widely discussed and debated. Although empirical data have revealed no improvement in productivity, those individuals who favour more investments in information technology argue that the information age is not an industrial age; therefore, new metrics to measure productivity are necessary and not necessarily the same as those of the industrial age. In addition, they argue that productivity is an output of many other factors in addition to information technology. This debate also calls for the proper evaluation of information systems usage; otherwise, the consequent effect may not be measured properly.

The productivity paradox dominated the debates in the early 1990s, which involved more developed countries than developing countries. Subsequently, a debate about the effect of information systems usage in developing countries emerged. Whereas one school of thought believes that developing countries can leapfrog from using information systems, i.e., there are positive effects of skipping some stages of development, negative effects are also prevalent; that is, information technology increases the gap between developing and developed countries because developing countries do not have the prerequisite infrastructure to support new technologies, and hence, their implementation may add more problems than it solves. However, effective usage of many new information technological tools may require high bandwidth and some necessary technological infrastructure that may not be present in some developing countries. In this regard, this study aimed to determine whether investment in information systems usage has any effect particularly a positive one - on performance.

\section{Statement of the research problem}

Congestion at the Dar es Salaam port has been a critical pressing and challenging constraint. This problem has had adverse effects on port operations and performance, which has resulted in tumbling revenue collections due to the divergence of some shipping lines and customers. This result maybe a reflection of subpar operational performance among port operators, where one factor is not leaving the port on time (Meersman et al. 2012). Over the past decades, solutions for many port information systems have been developed to improve ports' efficiency. These information systems solutions have been developed to improve efficiency and meet the increasing demands on ports without requiring the physical expansion of the ports in question (Ayfantopoulou et al. 2015). At a time when trade flows are down amidst rising competition, the possibility of making large-scale investments in port automation with a fleet of robots is typically challenging (Ikediashi et al. 2016). Due to the challenges and 
competitions of logistics performance in Tanzania, the study investigated the effect of information systems usage on port logistics performance at the Dar es Salaam port, which remains a serious concern for several port actors (Raballand et al. 2012, Daudi 2010, Kunaka et al. 2016).

\section{Objectives and significance of the study}

The main objective of this study was to investigate the role of information systems usage in boosting port logistics performance. Specifically, the work examined the role of information systems usage in contributing to the perceived decrease in shipping and trucking costs, improvements in timely delivery of goods and services, perceived increase in trade volume, and enhancement in organisational logistics capability at the Dar es Salaam port.

Considering the inherent high stakes, this study is important because the port has responsibility for all aspects of the logistics and supply chain in Tanzania and globally. First, the study findings empirically expose the positive effects of information systems usage on ports performance. Second, on the practical side, the study informs port management about how to appreciate information systems usage and the attendant implications. The research can also inform policy makers about the role of information systems usage in enhancing the operational performance of ports.

\section{Literature review}

\section{Theoretical framework}

This section provides theories that express the critical aspects of a successful technology and the urgency environment required for organisation performance. The models used in this study were task-technology fit and information systems success.

Task-technology fit theory contends that an information system is more likely to have a positive impact on individual performance and be used when the capabilities of the information system match the tasks that the user must perform (Goodhue and Thomson 1995). The proponents of this theory suggest various features that measure task-technology fit, which include quality, ability to use, system reliability, and profitability of the technology regarding the cost and time applied in delivering the service. This model could be useful in information systems facilities in the port, such as for software and other devices used to process customer information and all transactions that involve the clearing, forwarding, and logistics of the port cargoes. This model suggests that individual performance should match the task performed. The model has been widely tested and, to a great extent, has been found successful, with some moderating variables (Isaac et al. 2017, Chen and Huang 2017, Zha et al. 2018). Despite primarily focusing on individual performance, task-technology fit has been equally applied to organisations as a special case (Zigurs and Buckland 1998).

There are various models of information systems success, although those of DeLone and McLean (1992, 2003) are the most common ones. DeLone and McLean (1992, 2003) contend that information systems usage influences user information satisfaction and organisational impact through individual impact (DeLone and McLean 1992). Later, they redefined organisational impact through individual impact, constituting the net systems benefits (DeLone and McLean 2003). Despite their popularity, the DeLone 
and McLean success models have also attracted criticism. One of the most notable critical works is that of Seddon (1997), particularly regarding two issues: first, the meaning of information systems usage is unclear (Does the phrase imply benefitting from use? Does it refer to actual use? Does it involve probable future use?). Second, evaluating information systems success in terms of temporal and causal settings at the same time causes variance and process interpretations. However, Seddon (1997) proposes that information systems usage has individual, organisational and societal consequences. All the models concur that the usage influences the performance of organisation. Rai and others (Rai et al., 2002) tested these models and found that the models are relatively acceptable/valid despite other researchers commenting that the models do not necessarily have an impact (Lee 2012). The model has even been tested recently (Tam and Oliveira 2017, Van Cauter et al. 2017, Ojo, 2017).

This research is based on the assumption that the possible impacts are perceived decreased shipping and trucking costs (customers), timely delivery of goods and services (societal), perceived increased trade volume (organisational), and increased organisational logistics capability (organisational).

\section{Empirical reviews}

A large number of prior studies have addressed the information systems issue in the logistics or supply chain fields. These issues included the willingness to adopt, the outcomes of adoption, and the criteria for adoption (Panayides 2017; Heilig and Voß 2017; Tsai et al. 2018, Saxe 2018). New directions in terms of logistics and supply chain management are partially dictated by information technology (Li, 2014). Furthermore, port adoption and usage of information systems tends to enhance competitiveness (Panayides, 2017). As the issue of which factors drive usage has received significant attention, this study focuses on the effects of usage.

\section{Effect of information systems usage on logistical shipping and trucking costs}

Christopher (2005) studied and found that logistics performance increase when the members of the supply chain collaborate using Internet tools. Moreover, the study showed that poor information systems resource management has repercussions for the performance of the entire supply chain, leading to increased management costs.

Olugbode et al. (2008) conducted a case study that investigated the impact of the adoption of new information systems on the old model of company operation. Observation and interviews were used to collect the requisite data. The study revealed that the adoption of new information systems has led to different achievements in the company. The achievement appeared in company operational practices and business systems, which have reduced company operating costs. Almost all other studies found the same outcome (Mithas and Rust 2016, Carr 2016, Popa et al., 2016, Shahriari et al. 2016).

Thus, it is hypothesised that information systems usage reduces operating costs.

\section{Effects of information systems usage on timely delivery of goods and services}

Idris et al. (2013) conducted a study that investigated the roles of information systems usage in customer service delivery and firms' performance. The survey research design 
was applied to 25 firms. The study found that most of the customers rarely used online services in their engagement with firms. This study recommends that firm administrators to seek appropriate means of providing online services that parallel the customers' ability to apply the technology. The study's findings imply that the usefulness of information systems to an organisation depends significantly on how the user and recipient of the services interact when using such system.

Regan and Golob (2000) assessed the tracking industry perceptions of congestion problems and potential solutions in maritime intermodal operations. In all, 450 companies were surveyed. The study revealed that information systems hint at particular promise of reducing delays inside and outside the ports; however, the negative effect on trade is high due to congestion. The findings imply that congestion affects trading activities, whereas the adoption of information systems may reduce or alleviate the problem.

Adewoye et al. (2011) investigated the role of investment in information systems on service delivery. The study observed that there is a close link between information systems usage and services delivery. The findings show that the adoption of information systems at a university allows different activities, such as examination processing, student registration and assignment provision, to be performed on time.

Obiri-Yeboah et al. (2013) assessed the types of technological facilities used by bank customers and the challenges they faced. The results showed that the knowledge customers had about the services affected the number of times they used the service and the number of times they visited bank branches. The study findings imply information systems have great contributions to service delivery on timely basis; however, the customers' knowledge about the technology also influenced the level to which customers used the technology.

It is therefore hypothesised that information systems usage enhances timely delivery of goods and services.

\section{Effect of information systems usage on increased trade volume}

Kia et al. (2000) investigated the significance of information technology in cargo handling operations. The study established that information systems become accurate in transferring and processing large volumes of data in international transport firms and port organisations. In addition, the study found that the efficient port operation depended much on the management's control of the information technology applied in services delivery. These findings imply that the proper use of information systems can bring about tremendous improvements in organisational operations.

Ikediashi et al. (2016) conducted a study about the level of use of information systems infrastructure in the construction industry and analysed the implications for construction management practice. A quantitative questionnaire survey was employed; the study analysed data from 148 respondents using multiple regression analysis. The study established managers as the primary users of information systems in terms of the variety of information technology devices in the construction industry, with foremen emerging as the least-frequent users of such technology. The study also established causal relationships between information systems use and project performance in the context of construction industry.

Daud-Norzaidi et al. (2007) prepared a paper regarding the impact of Internet application among middle managers in the port industry. The results showed that Internet 
application determines the level of performance among managers. Moreover, the study found that the knowledge managers have about the capability of the Internet translates into intensive use of the opportunities it engenders.

It is hypothesised that information systems usage increases trade volume.

\section{Effect of information system usage on organisation capability}

Bryan-Jean et al. (2008) performed a study that examined the role of information systems in the context of international business and their contribution to supply chain performance. A qualitative approach guided a study with a desk review serving as a major data collection method. The study established that information systems' capabilities contribute directly to improved organisational processes, such as co-ordination, transactions, specific investments, absorptive capacity and monitoring. These improvements, in turn, contribute to strategic and operational performance outcomes. Against both a resource-based and a transaction-cost theoretical background, it was suggested that partner interdependence and environmental, country and cultural factors moderate the process of information technology contributing to performance. Although this study revealed that information technology has a positive impact on organisational performance, the study did not show how this effect occurs, which this study attempts to determine.

Hawajreh and Sharabati's (2012) study the influence of information technology on knowledge management practices in Jordan's industrial companies. Practical data were collected from 206 out of 1242 companies using a questionnaire. The results of the study indicate that there was a positive relationship between information technology and knowledge management practices. The study concluded that information technology and knowledge management practices are important sources of an organisation's wealth and therefore should be taken into account when formulating the company's strategy.

Ringim et al. (2012) study mainly focused on determining the effects of information technology capability on the organisational performance of Nigerian banks. Data were collected via hand delivery of questionnaires. Using a probabilistic procedure in selecting the organisations as the sample, the findings showed that information technology capability is related to the organisational performance of banks based on resource based view of such organisational performance.

It is therefore hypothesised that information systems usage improves organisational capabilities.

\section{Research gap and conceptual framework}

The literature reviewed shows that there no thorough study on the role of information system usage in port logistics performance has been performed. In fact, the literature has exhibited little concern about the direct impact of information systems usage on the service delivery associated with the port logistics performance. Previous studies concentrated mainly on the influence of information systems usage on organisations in general. Therefore, this study examines the role of information system usage in enhancing port logistics performance.

The conceptual framework guiding the study is presented in Fig. 1, which describes information systems usage as accelerating port performance measured in terms of decreased shipping and trucking costs, on-time service delivery, increased trade volume, 


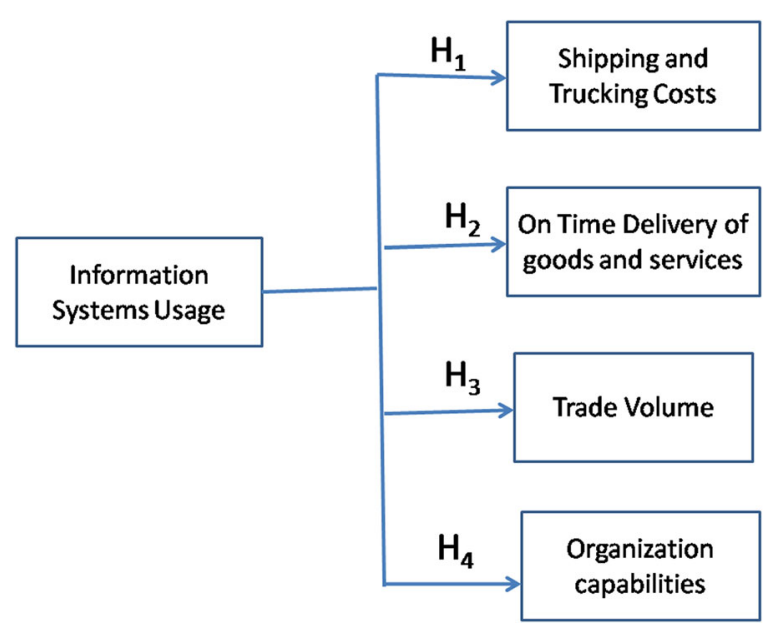

Fig. 1 Conceptual Framework. Developed by researchers from literature review

increased organisational capabilities, and improved service delivery, attributes that are also affected by information systems usage.

\section{Hypotheses of the study}

The study was guided by four hypotheses:

Hypothesis 1: $\mathrm{H}_{1}$-Information systems usage results in decreased shipping and trucking costs on logistics.

Hypothesis 2: $\mathrm{H}_{1}$-Information systems usage results in on-time delivery of goods and services.

Hypothesis 3: $\mathrm{H}_{1}$-Information systems usage results in increased trade volume for logistics.

Hypothesis 4: $\mathrm{H}_{1}$ - Information systems usage results in increased organisational capabilities in terms of logistics.

\section{Research methodology}

\section{Research design}

Positivism philosophy was used, especially to verify what researchers have said about the role of information systems usage in enhancing port performance. This work employed a cross-sectional study design. This design was deemed appropriate due to the nature of the research and research area. Moreover, the study employed a quantitative approach, with questionnaires deployed to gather information; the quantitative research was meant to determine whether the role of information systems usage found by other researchers might also be applicable in the case of the Dar es Salaam port.

The research design could have been performed using secondary data. Although data on the performance of the port over the years were available, it was difficult to attribute the increase or decrease to the use of information systems.

For convenience, the research used the Dar es Salaam port as a source of data. Thereafter, three strata were created for the main three actors at the port: port employees, 
revenue authority staff members, and clearing and forwarding agencies. Due to the nature of this study, close-ended questionnaires based on the Likert scale of measurement were used. The Likert scale was used to measure the respondents' opinions/attitudes, as commonly practised in social science research (Boone and Boone 2012). The attendant questions sought to establish the extent/level to which the respondents agreed or disagreed with a particular assertion. The scale used was strongly agree, agree, not sure/undecided, disagree, and strongly disagree.

\section{Sampling}

The population of this study is all ports in Africa or developing countries. For convenience, the Dar es Salaam port was taken as a case example. Thereafter, three users of the ports were selected to respond to the questionnaire. These users were importers/ exporters/transporters, clearing agents/port terminal operators, information and communication technology officers/information development officers and other ordinary employees. The researchers did not choose to concentrate on port employees only, as they may have decided to answer questions in their own favour (and hence introduced an element of bias). The self-administered questionnaires were left with the supervisors who distributed them to their subordinates/peers.

\section{Reliability and validity}

Cohen et al. (2013) treat reliability as the consistency of data over time, which also constitutes an accurate representation of the total population under study. Reliability entails obtaining the same results or data when the research is repeated using the same methods. On the other hand, validity is the capacity of the research tools to measure what they are designed to measure. In this study, efforts were made to ensure that the research instruments were both valid and reliable. In this regard, the study used Cronbach's alpha to assess reliability and pre-tested the questionnaire for validity.

To provide evidence that the components of the scale are sufficiently inter-correlated and that the grouped items measure the underlying variable, Cronbach's alpha was employed. The Cronbach's alpha reliability coefficient normally ranges between 0 (worst) and 1 (best).

This study used two out of six validity tests from Nelson and Ghods (1998), which were theoretical meaningfulness of the concepts and observational meaningfulness of concepts through pretesting the questionnaire (seeking other expert opinion about the questionnaire) and pilot testing (administering the questionnaire on a small scale to check whether the questions were clear).

\section{Data analysis techniques}

The data collected for each of the five variables were combined by computing the average after verifying that they correlated. Perhaps factor analysis would have been better; however, it was not used in this study because it would have provided five uncorrelated factors. These summed scores were used in canonical correlations. Canonical correlation analysis, having foundations based on Pearson correlation, is a classical multivariate data method for establishing correlations between two multivariate data sets. In this 
study, canonical correlation analysis was used to estimate the effect of information systems usage in port logistics performance on the four criterion variables.

\section{Operationalisation of the concepts}

The study applied concepts generated from other studies. The concepts were reframed to match with the existing situation in Tanzania. Moreover, the concepts were adapted from other studies primarily because the role of information systems usage in port logistics performance is not a new concept among researchers; rather, its efficiency varies depending on the organisational capabilities of each institution.

\section{Information systems usage as a predictor variable}

Brynjolfsson and Hitt (2000) define an information system as a computer and related digital communication technology that has extensive power to reduce the costs of using information technology in the following task or activity co-ordination, communication, and information processing. The study determined to what extent the port's tasks or activities benefiting from the application of information technology are effective in terms of hours and days spent on computers. Although the authors of this paper acknowledge the meaning of usage as advocated by Seddon (1997), this work focuses on the actual usage due to the nature of this study.

Information systems usage was measured based on the time and duration spent on performing duties in the office using the appropriate information systems, the processing time and the dependence of information systems performing tasks.

\section{Shipping and trucking cost as a criterion variable}

The study used the definition of shipping and trucking cost by Austin (2015), who defined it as the price incurred at which a certain cargo is delivered from one point to another. This price is much affected by the goods delivering process and the distance to the delivery destination. The major concern was to see how information systems facilitated the reduction of the waiting time, the delivery cost, and the storage time, which decrease as a result of on-time cargo operations. The trucking and shipping cost of logistic performance was measured using the waiting time, movement of the ships, the delivery costs and storage time.

\section{On-time delivery of goods and service as a criterion variable}

The study adopted the definition by Gunasekaran et al. (2004), which describes on-time delivery as a measure of process and supply chain efficiency that measures the amount of finished goods or services delivered to the customers on time and in full. The study looked at the extent to which the technology managed to facilitate time discharge and the transaction process of cargo and services as well as the movement of the ships and trucks. On-time delivery of goods and services was measured through the simplifications of transactions, mobility of ships and trucks, and decreases in service delivery costs.

\section{Trade volume as a criterion variable}

The study used a definition by Young and others (2008) of trade volume as the total quantity of shares or contracts traded in a specified time. It measures how much of a 
given financial asset has been traded in a given period. In this regard, the study determined to what extent new technology managed to shorten the waiting time of ships and port customers, managed to increase the productivity, and managed to link the Dar es Salaam port with other ports. The trade performance/ volume was measured by looking at the enhanced efficiency, waiting time, turn around, connectivity, and the discouragement of idleness in port operations.

\section{Organisational capability as a criterion variable}

The concept of organisational capability was applied to infer the company's ability to manage resources such as employees to gain an effective advantage over competitors (López-Cabarcos et al. 2015). As such, the company needs to focus on the business' ability to meet customer demand. López-Cabarcos et al. (2015) argue that organisational capabilities must be unique to the organisation to prevent replication by competitors. Hence, this study focused on how information systems usage impacts the operations at the port of Dar es Salaam. These organisational capabilities were measured in terms of effective communication among the workers, the adequate awareness of the new applied information technology, increased intrinsic motives of the workers to provide standard service, tendencies of knowledge sharing from external resources on the new adopted technology, staff being able to apply the new adopted information technology, and co-ordination in running organisation's activities.

\section{Other variables}

The study captured the respondents' demographics, including age, gender, education and others, to determine whether the sample selected represented the population of the study.

\section{Findings and discussion}

\section{Sample profile of the research study}

The study captured both gender attributes of males and females in the field. The data collected revealed that the number of male respondents was more than double that of the female respondents who provided information for the study (Table 1).

The study had four age groups. The groups were 18-30, 31-40, 41-55 and above 55 years. The data collected indicated that half of respondents were aged between 31 and 40 years. As expected, the oldest group of those close to the retirement age was rather few in number, less than $5 \%$.

Furthermore, the sample data showed that the three occupations were nearly uniformly distributed. This suggests that all the occupations had access to the usage of information in their daily operations.

More than one-third of the respondents were diploma holders (34\%). This group was followed degree holders, who represented approximately one-sixth (17.9\%). Holders of masters degrees and those who left secondary school amounted to 9.4 and $6.6 \%$, respectively. On the other hand, $\mathrm{PhD}$ holders had a relatively higher representation at $12.3 \%$, which was well above the operational workforce holding only certificates and diplomas.

\section{Information systems usage}

The respondents were also asked to estimate the hours spent using information systems (Table 2). Nearly two-thirds of the respondents reported spending at least $6 \mathrm{~h}$ per 
Table 1 Respondents' profile

\begin{tabular}{lll}
\hline & Frequency & Percent \\
\hline Sex & 68 & 64.2 \\
Male & 32 & 30.2 \\
Female & & 17.0 \\
Age group & 18 & 51.9 \\
18-30 years & 55 & 20.8 \\
31-40 years & 22 & 4.7 \\
41-55 years & 5 & 24.5 \\
Above 55 years & & 27.3 \\
Occupation & 26 & 27.3 \\
Importer/ Exporters/Transporters & 29 & 15.1 \\
Clearing agent/Port Terminal Operators & 29 & \\
ICT officers/Information development Officers & 16 & 20.8 \\
Ordinary employees & & 34.0 \\
Education level & 22 & 17.9 \\
Secondary level/Certificates & 36 & 9.4 \\
Diploma & 19 & 12.3 \\
Degree & 10 & \\
Masters & 13 & \\
PhD & & \\
\hline Source:Data Analys & 36 & \\
\hline
\end{tabular}

Source: Data Analysis

day. A considerable number of the respondents of slightly above one-fifth reported accessing and using information systems 8 or more hours per day. On average, information systems usage on a daily basis was common among the port employees.

The majority of the respondents (83\%) spent 5 days or more using information systems (Table 3). This result means that they commonly use information systems throughout the working days in a week. Thus, high logistics performance is likely to be attained in the operations of the port.

The data in Table 4 indicate that three-quarters of the respondents reported that their time to process the working data was less than $3 \mathrm{~min}$. More than $3 \mathrm{~min}$ of processing time was reported by a few. This usage could directly lead to on-time delivery of goods and services, in addition to reducing trucking and shipping costs.

The use of information systems is slightly equally distributed in a number of areas of the port's logistics operations (Table 5). Most likely, this distribution use of the systems depends on working section and department to which the respondent belongs. However, it appears the respondents trucking cargos use information systems more than other respondents responsible for other logistical operations at $29 \%$.

\section{Reliability analysis}

Before proceeding with the canonical correlation analysis to determine the extent to which the items in the questionnaire relate to each other, an overall index of the repeatability or the internal consistency of the scale as a whole was computed to identify 
Table 2 Hours Spent on Using Information Systems in Performing Duties

\begin{tabular}{lll}
\hline & Frequency & Percent \\
\hline $0-1$ h per day & 10 & 10.0 \\
$2-3$ h per day & 20 & 20.0 \\
$4-5$ h per day & 7 & 7.0 \\
$6-7$ h per day & 42 & 42.0 \\
8 h and above per day & 21 & 21.0 \\
Total & 100 & 100.0 \\
\hline
\end{tabular}

Source: Data Analysis

problem items that should be excluded from the scale. Based on the average inter-item correlation, alpha (Cronbach's) was used as a model to determine internal consistency. There were four sets of data whose internal consistence was determined. The data in Table 6 indicate that the computed Cronbach's alpha coefficients were all acceptable, an indication of good internal consistency of the items in the scale (George and Mallery 2003).

\section{Canonical correlation analytical results}

A canonical correlation analysis was conducted using the information systems usage variable as predictor on the four logistics performance variables as criterion variables to evaluate the multivariate shared relationship between the two variable sets. The full canonical model was evaluated for statistical significance. The approach was based on Roy's greatest root (Table 7). The most common method used is Wilks' lambda $(\lambda)$, as it tends to have the most general applicability (Sherry and Henson 2005). In this case, the full model was significant, with a Wilks' $\lambda$ of $0.264, F(4,95)=66.364$, and $p<.001$.

An overall effect for the full model was computed. Wilks' $\lambda$ has a useful property that informs about this issue because it represents something of an inverse effect size or the amount of variance not shared between the variable sets. Therefore, by taking $1-\lambda$, one can find the proportion of variance shared between the variable sets across all the functions. This effect statistic was interpreted in a way similar to the multiple $R^{2}$ in regression. In this case, $\mathrm{R}^{2}$ is 0.736 , which indicates high explanatory power of the model.

Each canonical function must be evaluated to determine the function that explains much of the relationship between the variable sets (Table 8). Each function may not contribute much to the total solution; however, the cumulative total solution may be significant and perhaps noteworthy. In this case, the first canonical function was

Table 3 Days Spent per Week Using the Information System in Performing Duties

\begin{tabular}{lll}
\hline & Frequency & Percent \\
\hline 1 day per week & 1 & 1.0 \\
2 days per week & 2 & 2.0 \\
3 days per week & 7 & 7.0 \\
4 days per week & 7 & 7.0 \\
5 days and above per week & 83 & 83.0 \\
Total & 100 & 100.0 \\
\hline
\end{tabular}

Source: Data Analysis 
Table 4 Time Taken to Process the Working Data

\begin{tabular}{lll}
\hline & Frequency & Percent \\
\hline $0-1 \mathrm{~min}$ & 21 & 21.0 \\
$2-3 \mathrm{~min}$ & 56 & 56.0 \\
$4-6 \mathrm{~min}$ & 16 & 16.0 \\
$7-10 \mathrm{~min}$ & 7 & 7.0 \\
Total & 100 & 100.0 \\
\hline
\end{tabular}

Source: Data Analysis

interpreted as it explains $73.6 \%$ of the variance within the functions (Table 8). This result means that this relationship was largely captured by the first function in the canonical model. Therefore, there was a noteworthy relationship between our variables' sets from the evidence of significance and effect sizes.

An analysis to test how well the data fit the created model was also conducted. Table 9 provides these figures. The data fit well with the model created (53\% to $73 \%$ ).

The results in Table 10 indicate that coefficients for the function indicate that three criterion variables (on-time delivery, trucking and shipping costs, and organisational capability) contributed to the model significantly. On the other hand, trade volume contributed less to the model. This result was supported mainly by the squared structure coefficients, which indicated the amount of variance the variable observed can contribute to the synthetic criterion variable. All of these variables' structure coefficients had the same positive sign, indicating that they were all positively related. The other side of the equation in Function 1 involves the predictor variable. The results in Table 10 inform us that organisational capability, as a proxy for information usage, contributed to the predictor set of variables. The predictor variable was positively related to the criterion variables. These results suggest the expected relationship between the information usage and logistics performance.

Table 11 summarises the results of the data analysis.

\section{Conclusions and implications}

The study investigated the role of information systems usage in enhancing port logistics performance in Tanzania using the case of the Dar es Salaam port. The study employed descriptive analysis to capture information about the sample characteristics and the pattern of the information systems usage at the Dar es Salaam port. Canonical correlation analysis was used to test the hypotheses regarding the relationship between the logistics performance of the port and information systems usage.

Table 5 Reasons for Information Systems Usage

\begin{tabular}{lll}
\hline & Frequency & Percent \\
\hline Organization planning & 22 & 22.0 \\
Billing of port services & 15 & 15.0 \\
Trucking cargos & 29 & 29.0 \\
Cargo reconciliation & 20 & 20.0 \\
Bill payment & 14 & 14.0 \\
Total & 100 & 100.0 \\
\hline
\end{tabular}

Source: Data Analysis 
Table 6 Reliability Statistics Results

\begin{tabular}{llll}
\hline Data Sets & $\begin{array}{l}\text { Cronbach's } \\
\text { Alpha }\end{array}$ & $\begin{array}{l}\text { Cronbach's Alpha Based on Standardized } \\
\text { Items }\end{array}$ & $\begin{array}{l}\text { N of } \\
\text { Items }\end{array}$ \\
\hline $\begin{array}{l}\text { Decreased shipping and trucking } \\
\text { costs }\end{array}$ & 0.725 & 0.744 & 6 \\
$\begin{array}{l}\text { Timely delivery of goods and } \\
\text { services }\end{array}$ & 0.775 & 0.784 & 4 \\
$\begin{array}{l}\text { Trade volume } \\
\text { Organizational Capability }\end{array}$ & 0.730 & 0.744 & 6 \\
\hline
\end{tabular}

Source: Data Analysis

Before proceeding with the canonical correlation analysis, the study determined the extent to which the items in the questionnaire were related to each other. In this regard, an overall index of the repeatability or internal consistency of the scale as a whole was computed to identify problem items that should be excluded from the scale. The computed Cronbach's Alpha coefficients were all acceptable, an indication of the good internal consistency of the items on the scale.

A canonical correlation analysis was conducted using one information systems usage variable as predictor of the four logistics performance variables. The full canonical model was evaluated for statistical significance with the prepared multivariate sets. Four methods were used to compute the significance of the model, yielding four sets of statistics.

A dimension reduction analysis was conducted to test the hierarchal arrangement of the functions for statistical significance. Each canonical function was evaluated to determine the function that explains much of the relationship between the variable sets. A noteworthy relationship was found between variable sets based on the evidence of statistical significance and effect sizes.

\section{Conclusion obtained from findings about the key research objectives}

Influence of information systems usage on decreased shipping and trucking costs

The first objective of the study was to determine whether information system usage contributes to a reduction in shipping and trucking costs pertaining to logistics performance at the Dar es Salaam port. The analysis of the findings shows that information systems usage at the port greatly accelerates reduction in shipping and trucking costs. This relationship is justified, as the research results revealed a strong relationship among the three variables. These findings support Christopher's (2005) assertion that the collaboration of members of the supply chain through Internet tools can enhance the logistics performance. Hence, information systems resource management has

Table 7 Statistical Significance Tests for the Full Canonical Correlation Analysis Model

\begin{tabular}{llllll}
\hline Test Name & Value & Exact & Hypoth. DF & Error DF & Sig. of F \\
\hline Pillai's & 0.736 & 66.364 & 4.00 & 95.00 & 0.000 \\
Hotelling's & 2.794 & 66.364 & 4.00 & 95.00 & 0.000 \\
Wilk's & 0.264 & 66.364 & 4.00 & 95.00 & 0.000 \\
Roy's & 0.736 & & & & \\
\hline
\end{tabular}

Multivariate Tests of Significance $(S=1, M=1, N=461 / 2)$ Source: Data Analysis 
Table 8 Eigenvalues and Canonical Correlations

\begin{tabular}{lccccc}
\hline Root No. 1 & Eigenvalue & Pct. & Cum. Pct & Canon Cor. & Sq. Cor. \\
\hline 1 & 2.794 & 100.000 & 100.000 & .858 & .736 \\
\hline Source: Data Analysis & & & &
\end{tabular}

repercussions for the performance of the entire supply chain since its nature of functionality determines the management cost.

Influence of information system usage on timely delivery of goods and services

The second objective of the study focused on establishing whether information systems usage influence on-time delivery of goods and services on logistics at the Dar es Salaam port. The findings of the study reveal that two variables have a greater relationship, hence signifying that information systems usage highly influences on-time delivery of goods and services. Furthermore, the findings of the study concur with what was unveiled in the study by Kia et al. (2000), which demonstrated that improved information technology opens wide options for container terminal operators to operate the attendant information systems by enabling the port to provide the service on a timely basis and accurately. Therefore, it can be asserted that the efficiency of the port in delivering the services is connected with the technology available.

\section{Influence of information system usage on increased trade volume on logistics}

The third objective of the study focused on examining whether information systems usage contributes to increased trade volume on logistics performance at the Dar es Salaam port. The analysis of the findings indicates that information systems usage moderately influences trade volume since the effect registered was far lower that the results for other variables. Kia et al. (2000) showed that information systems are becoming increasingly accurate in transferring and processing large volumes of data involved in international transportation firms and port organisations. However, the findings of this study indicate that information systems usage moderately increase its trade volume. In fact, the results suggest that the trade volume increase is linked not only to one factor but also to other factors in the general chain, such as the trade policy of the country and many others.

Influence of information system usage on increased Organisational capability

The fourth and final objective of the study aimed to ascertain whether information systems usage contributes to increased organisational capability in terms of logistics performance at the port of Dar es Salaam. The findings reveal that information systems

Table 9 Strength of the Models Created

\begin{tabular}{lllllll}
\hline Variable & Sq. Mul. R & Adj. R-sq. & Hypoth. MS & Error MS & F & Sig. of F \\
\hline Decreased shipping and trucking costs (C) & 0.723 & 0.721 & 36.260 & 0.142 & 256.257 & 0.000 \\
Timely delivery of goods and services (TD) & 0.555 & 0.551 & 50.534 & 0.413 & 122.383 & 0.000 \\
Trade volume (TP) & 0.526 & 0.521 & 25.271 & 0.233 & 108.571 & 0.000 \\
Organizational Capability (OC) & 0.533 & 0.528 & 25.886 & 0.232 & 111.671 & 0.000 \\
\hline
\end{tabular}

Source: Data Analysis 
Table 10 Canonical Solution for Information Systems Usage on Logistics Performance

\begin{tabular}{|c|c|c|c|c|c|c|c|}
\hline Covariate Variable & B & Beta & Std. Err. & t-value & Sig. of $\mathrm{t}$ & Lower & Upper \\
\hline \multicolumn{8}{|c|}{ Dependent variable: Decreased shipping and trucking costs (C) } \\
\hline Information Systems Usage & 1.196 & 0.851 & 0.075 & 16.008 & 0.000 & 1.047 & 1.344 \\
\hline \multicolumn{8}{|c|}{ Dependent variable: Timely delivery of goods and services (TD) } \\
\hline Information Systems Usage & 1.412 & 0.745 & 0.128 & 11.063 & 0.000 & 1.158 & 1.665 \\
\hline \multicolumn{8}{|c|}{ Dependent variable: Trade volume (TP) } \\
\hline Information Systems Usage & 0.998 & 0.725 & 0.096 & 10.420 & 0.000 & 0.808 & 1.188 \\
\hline \multicolumn{8}{|c|}{ Dependent variable: Organizational Capability (OC) } \\
\hline Information Systems Usage & 1.010 & 0.730 & 0.096 & 10.567 & 0.000 & 0.821 & 1.200 \\
\hline
\end{tabular}

usage as a predictor contributes a great deal to enhancing organisational capability. According to Daud-Norzaidi et al. (2007), information systems usage determines the level of performance among the workers. The findings indicate that the technology applied fits the organisation's needs, as the task-technology fit model works on the assumption that an information system is more likely to have a positive impact on individual performance and usability when the capabilities of the system match the tasks that the user must undertake (Goodhue and Thomson 1995).

\section{Conclusion about the effect of information systems usage on the performance of ports}

Over the past decades, many information system solutions for ports have been developed to boost their efficiency. Although this has the case for a long period, logistics performance in Tanzania has continued posing a large challenge that induced the management to adopt the new governance (adoption of modern information technology). Therefore, this study opted to examine the role of information systems in logistics performance at the port of Dar es Salaam. Based on the findings, the study affirms that adoption of information systems can enhance on-time delivery of services and goods, reduce trucking and shipping costs, and increase organisational capability. On the other hand, the study found limited correlation between information systems usage and increased trade volume, which implies that trade volume is a variable that needs an integration of many other factors instead of relying on information systems usage alone.

\section{Implications for theory}

The research findings complement the technology acceptance model, since on-time delivery can be attained from building the capacity of information systems usage of port workers. The reduction registered in trucking and shipping costs can be guided by the

Table 11 Summary of Data Analysis

\begin{tabular}{lll}
\hline Relationship between Information Systems Usage and & Statistical support & Strength of support \\
\hline Decreasing shipping and trucking costs on logistics & Supported & Very Strong (almost three quarters) \\
On time delivery of goods and service & Supported & Strong (almost 50\%) \\
Increasing trade volume on logistics & Supported & Strong (almost 50\%) \\
Increasing organization capabilities on logistics & Supported & Strong (almost 50\%) \\
\hline
\end{tabular}


actual utilisation of the information system facilities. The outcomes of information systems usage on port logistics performance can be realised through the usefulness and user-friendliness of the system. After all, the technology acceptance model is based on the easy application and the inherent cost-efficiency of the technology.

The task-technology fit theory, on the other hand, insists on individual's performance matching with the task he/she performs. This theory is liable to have a positive impact on individual performance and usability particularly when the capabilities of information systems match the tasks that the user must perform. Features are used to measure task-technology fit, including quality, ability to use, system reliability, profitability of the technology regarding the cost and time required for delivering service. In this regard, the research findings indicate that reliable information coupled with a proper quality system and capable users can help achieve strong on-time delivery. A reduction in trucking and shipping costs can also be achieved through proper utilisation of technology in terms of the cost and time require for service delivery.

\section{Implications for policy and practice}

The work has shown that information systems usage does influence performance. As such, it is important for policy-makers and practitioners to encourage information systems usage in a bid to improve performance.

There are a number of empirical implications from this study regarding the information systems usage in port management. The study has demonstrated that information systems usage has positive effects on the performance of ports. Thus, the management of ports must work hard to implement information systems and motivate employees to use these systems. Such systems can influence the performance of ports positively and improve efficiency. In fact, the ports that adopt and use information systems have greater prospects of decreasing shipping and trucking costs than those not using such systems. Other benefits include timely delivery of goods and services, perceived increased trade volume, and increased organisational logistics capability.

In addition, it is important for regulatory bodies to influence the adoption and application of such information systems. Because the study suggests more usage translates into better performance, it is important to integrate various systems that will help yield even more usage. In fact, well-interlinked developed information systems, for example, with banks, revenue authorities and others, will increase the information systems' usage and hence further enhance performance.

\section{Limitations of the study and implications for further studies}

This study targeted four independent variables (on-time delivery, trade volume, trucking and shipping costs, and organisational capability) to explain their relationship with information systems usage. Of these four variables, information systems usage was found to have a minimal role in increasing the trade volume performance; therefore, other studies must be performed to determine the factors that affect the increase in trade volume at the port.

This study has showed that higher usage of logistic information systems implies better port logistics performance measured in terms of the four variables only (reduction 
of shipping and trucking costs, improving on-time delivery of goods and services, increasing trade volume, and enhancing organisational logistics capability). The assumption is that the more time an organisation spends on information systems, the more it will be able to increase the degree of adoption and hence port performance. This study measured usage in terms of port dependence on information systems for day-to-day operations.

\section{Additional file}

Additional file 1: Data that were used for analysis. (SAV $13 \mathrm{~kb}$ )

Acknowledgements

We have no further acknowledgements to make.

Funding

The project was part of dissertation submitted to the University of Dar es Salaam by James Mlimbila for award of Master of Science in International Transport and Logistics of the University of Dar es Salaam, Tanzania.

\section{Availability of data and materials}

Data supporting this document is appended to the submission as Additional file 1.

\section{Authors' contributions}

All authors participated in background research, study design," and writing of this paper. All authors read and approved the final manuscript.

\section{Competing interests}

The authors declare that they have no competing interests.

\section{Publisher's Note}

Springer Nature remains neutral with regard to jurisdictional claims in published maps and institutional affiliations.

Received: 6 April 2018 Accepted: 17 September 2018

Published online: 05 October 2018

\section{References}

Adewoye JO, Ayo CK, Oni AA, Adebiyi AA (2011) The impact of IT investment on service delivery: a case study of Ladoke Akintola University. J Emerg Trends Educ Res Policy Stud 2(1):60-66

Ally N, Mbamba U (2009) The effect of ICT on service quality perception and customer satisfaction: the case of ICTenabled Services in Selected Banks. Afr J Financ Manag 28(2):78-92

Arnold, J., Mathenge, J., Dihel, N., Strychacz, N. (2011). The role of clearing and forwarding agents in reforming the EAC logistics sector. African Trade Policy Notes. EAC, Arusha

Austin D (2015) Pricing freight transport to account for external costs. Congressional Budget Office, Washington DC Ayfantopoulou, G., Tsoukos, G., Stathacopoulos, A., Bizakis, A., Gagatsi, E. (2015). Greener Port Performance Through ICT. In Springer, Sustainable Development of Sea-Corridors and Coastal Waters (pp. 207-215). Springer International Publishing, Switzerland

Boone HN, Boone DA (2012) Analyzing likert data. J Ext 50(2):1-5

Bryan-Jean RJ, Sinkovics RR, Kim D (2008) Information technology and organizational performance within international business to business relationships: a review and an integrated conceptual framework. Int Mark Rev 25(5)

Brynjolfsson E, Hitt LM (2000) Beyond computation: information technology, organizational transformation and business performance. J Econ Perspect 14(4):23-48

Carr AS (2016) Relationships among information technology, organizational cooperation and supply chain performance. J Manag Issues 28(3/4):171-190

Chen YS, Huang SY (2017) The effect of task-technology fit on purchase intention: the moderating role of perceived risks. Jisk Res 20(11):1418-1438

Christopher M (2005) Logistics and supply chain management: creating value-added networks. Prentice Hall, Harlow, England

Cohen, L., Manion, L., Morrison, K. (2013). Research methods in education. Routledge, London

Daudi DG (2010) The role of ICT in tracking and tracing of containers at the Dar es Salaam port. PhD Thesis University of Dar es Salaam, Dar es Salaam

Daud-Norzaidi M, Choy-Chong S, Murali R, Intan-Salwani M (2007) Intranet usage and managers' performance in the port industry. Ind Manag Data Syst 107(8):1227-1250

DeLone WH, McLean ER (1992) Information systems success: the quest for the dependent variable. Inf Syst Res 3(1):60-95

DeLone WH, McLean ER (2003) Information system success: the quest for the dependent variable. Inf Syst Res 19(4):10-25

George D, Mallery M (2003) Using SPSS for windows step by step: a simple guide and Country Studiesreference. Allyn and Bacon, Boston

Gidado U (2015) Consequences of port congestion on logistics and supply chain in African ports. Developing Cty Stud 5(6):160-167 
Goodhue DL, Thomson RL (1995) Task technology fit and individual performance. MIS Q:213-236

Gunasekaran A, Patel C, McGaughey RE (2004) A framework for supply chain performance measurement. Int J Prod Econ 87(3):333-347

Hawajreh KM, Sharabati A (2012) The impact of information technology on knowledge management practices. Int J Bus, Hum Technol 2(7):32-46

Heilig L, Voß S (2017) Information systems in seaports: a categorization and overview. Inf Technol Manag 18(3):179-201

Idris AA, Olumoko TA, Ajemunigbohun SS (2013) The role of information technology in customers' service delivery and firm performance: evidence from Nigeria's insurance industry. Int J Market Stud 5(4):59

Ikediashi DI, Ikediashi DI, Ogwueleka AC, Ogwueleka AC (2016) Assessing the use of ICT systems and their impact on construction project performance in the Nigerian construction industry. J Eng, Des Technol 14(2):252-276

Isaac O, Abdullah Z, Ramayah T, Mutahar AM (2017) Internet usage, user satisfaction, task-technology fit, and performance impact among public sector employees in Yemen. Int J Inf Learn Technol 34(3):210-241

Kia M, Shayan E, Ghotb F (2000) The importance of information technology in port terminal operations. Int J Phys Distrib Logist Manag 30(3/4):331-344

Kunaka C, Hartmann O, Raballand G, Shamte R (2016) Trade, logistics infrastructure, and regional integration. In: Tanzania: The Path to Prosperity, 105

Lee, R. C. (2012). Does the success of information systems really matters to firm performance?. iBusiness, 4(02):98

Li, X. (2014). Operations management of logistics and supply chain: Issues and directions. Discret Dyn Nat Soc, 2014:1-7, https://doi.org/10.1155/2014/701938

López-Cabarcos, M. Á., Göttling-Oliveira-Monteiro, S., Vázquez-Rodríguez, P. (2015). Organizational capabilities and profitability: the mediating role of business strategy. SAGE Open, 5(4):2015:1-13

Meersman, H., Van de Voorde, E., \& Vanelslander, T. (2012). Port congestion and implications to maritime logistics. In Maritime Logistics: Contemporary Issues (pp. 49-68). Emerald Group Publishing Limited, West Yorkshire

Mithas S, Rust RT (2016) How information technology strategy and investments influence firm performance: conjecture and Emirical evidence. MIS Q 40(1):223-245

Nelson KM, Ghods M (1998) Measuring technology flexibility. Eur J Inf Syst 7(4):232-240

Nowduri, S. (2011). Management information systems and business decision making: review, analysis, and recommendations. J Manag Market Res, 7(1):1-7

Obiri-Yeboah K, Kyere-Djan R, Kwarteng KO (2013) The role of information technology on banking service delivery: a perspective from customers in Ghana. Int J Innov Res Manag 2(6):1-12

Ojo Al (2017) Validation of the DeLone and McLean information systems success model. Healthcare Inf Res 23(1):60-66

Olugbode M, Elbeltagi I, Simmons M, Biss T (2008) The effect of information systems on firm performance and profitability using a case-study approach. Electron J Inf Syst Eval 11(1)

Panayides, P. M. (2017). Global supply chain integration and competitiveness of port terminals. In Ports, cities, and global supply chains (pp. 43-56). Routledge, UK

Pierson, D., Harner, R. (2006). US Patent No 11/407,54, US

Popa S, Soto-Acosta P, Perez-Gonzalez D (2016) An investigation of the effect of electronic business on financial performance of Spanish manufacturing SMEs. Technol Forecast Soc Chang

Raballand, G., Refas, S., Beuran, M., Isik, G. (2012). Why does cargo spend weeks in sub-Saharan African ports?: lessons from six countries. World Bank, Washington, US

Rai A, Lang SS, Welker RB (2002) Assessing the validity of IS success models: an empirical test and theoretical analysis. Inf Syst Res 13(1):50-69

Regan AC, Golob TF (2000) Trucking industry perceptions of congestion problems and potential solutions in maritime intermodal operations in California. Transp Res A Policy Pract 34(8):587-605

Ringim KJ, Razalli MR, Hasnan N (2012) The relationship between information technology capability and organizational performance of Nigerian banks. Int J Bus Res Dev 4(2)

Salin V (2000) Information technology and cattle-beef supply chains. Am J Agric Econ 82(5):1105-1111

Saxe S (2018) SmartPORT traffic hub-the prospects for an intermodal port of the future. In: Digital marketplaces unleashed. Springer, Berlin, Heidelberg, pp 417-426

Seddon PB (1997) A respecification and extension of the DeLone and McLean model of IS success. Inf Syst Res 8(3):240-253

Shahriari MR, Pilevari N, Gholami Z (2016) The effect of information systems on the supply chain sustainability using DEMATEL method. Commun Adv Comput Sci Appl (1):47-56

Sherry A, Henson RK (2005) Conducting and interpreting canonical correlation analysis in personality research: a user friendly primer. J Pers Assess 84(1):37-38

Tam C, Oliveira T (2017) Understanding mobile banking individual performance: the DeLone \& McLean model and the moderating effects of individual culture. Internet Res 27(3):538-562

Tanzania Ports Authority. (2017). Dar Es Salaam and central Coast Sea ports. Retrieved from Tanzania Ports Authority: https://www.ports.go.tz/index.php/en

Tsai JY, Ding JF, Liang GS, Ye KD (2018) Use of a hybrid MCDM method to evaluate key solutions influencing service quality at a port logistics center in Taiwan. Brodogradnja: Teorijaipraksabrodogradnjeipomorsketehnike 69(1):89-105

Van Cauter, L., Verlet, D., Snoeck, M., \& Crompvoets, J. (2017). The explanatory power of the Delone \& McLean model in the public sector: A mixed method test. Information Polity, 22(1):41-55

Weiss, K. D. (2011). Building an import/export business. John Wiley \& Sons, NJ, US

Wilson DM, Iravo MA, Tirimba Ol, Ombui K (2015) Effects of information technology on performance of logistics firms in Nairobi County. Int J Sci Res Publ 5(4):1-26

Young K, Sun Q, Rahman H (2008) Trade Volume and Overconfedence with Different Information and Heterogeneous Investor. Alliant International University.

Zha X, Yang H, Yan Y, Liu K, Huang C (2018) Exploring the effect of social media information quality, source credibility and reputation on informational fit-to-task: moderating role of focused immersion. Comput Hum Behav 79:227-237

Zigurs, I., Buckland, B. K. (1998). A theory of task/technology fit and group support systems effectiveness. MIS quarterly, 22(3): $313-334$ 